\title{
Síntese histórica e socioambiental do Parque Nacional da Chapada das Mesas (MA)
}

\section{Historical and socio-environmental synthesis of the Chapada das Mesas National Park (MA, Brazil)}

\author{
Maria Lindalva Alves da Silva, Maria de Fátima Veras Araujo, \\ Gonçalo Mendes da Conceição
}

\begin{abstract}
RESUMO: O processo de criação da Unidade de Conservação surgiu em decorrência de uma demanda socioambiental, na qual a população temia a construção de duas pequenas hidrelétricas nas cachoeiras que ficam no interior da região, onde atualmente se criou o Parque Nacional Chapada das Mesas. O objetivo do estudo é apresentar um breve histórico do surgimento socioambiental do Parque Nacional da Chapada das Mesas, desde os primeiros indicativos pelos técnicos do Projeto RADAMBRASIL, até os movimentos com entidades ambientais, que lutaram em prol da proposta de sua criação. O estudo tem caráter descritivo, com abordagem qualitativa, com aplicação de entrevista semiestruturada com roteiro pré-estabelecido. Os resultados mostraram que a recém-criada Unidade de Conservação teve seus primeiros indicativos de criação na década de 1970, sendo intensificada a partir dos anos 2000 , culminando com sua implantação em 2005.
\end{abstract}

PALAVRAS-CHAVE: Preservação; Unidade de Conservação; Turismo Sustentável.

\section{ABSTRACT}

The creation process of Conservation Unit arised in consequence of a socioenvironmental demand, where the people dreaded the construction of two little hydroelectricity in the waterfall that stay inside of the region, where current created the Chapada das Mesas National Park. The objective of the study is to present a brief history of the socioenvironmental emergence of the Chapada das Mesas National Park, from the first indications by the technicians of the RADAMBRASIL Project, to the movements with environmental entities that fought for the proposal of its creation. The study is descriptive, with a qualitative approach, with a semi-structured interview with a pre-established script. The results showed that the newly created Conservation Unit had its first indicative of breeding in the 1970s, being intensified from the 2000s, culminating with its implementation in 2005.

KEYWORDS: Preservation; Protect Area; Sustainable Tourism. 


\title{
Introdução
}

O território maranhense é composto pelos domínios fitogeográficos do bioma Cerrado, Floresta Amazônica e por manchas de Caatinga, o que Ihe atribui grande diversidade de espécies e ambientes únicos, com riqueza de atributos naturais (MUNIZ, 2006). Os recursos hídricos, em torno de $(2,8 \%)$, são constituídos pelas águas superficiais como rios, lagos, lagoas e barragens e as subterrâneas, o que corresponde $97,2 \%$ das encontradas nas nascentes naturais e lençóis de águas existentes no subsolo (MARANHÃO, 2011). Portanto, observa-se que esse território é formado por inúmeros corpos d'água, se tornando um dos estados nordestinos que menos sofre com escassez de água para o uso humano. A água também é usada na produção agrícola e plantação de pastagens para a criação de animais como bovinos, tornando-se um Estado que apresenta uma diversidade de fisionomias pela heterogeneidade de sua vegetação (MARQUES; AMORIM, 2014).

De acordo com o Instituto Brasileiro de Geografia e Estatística, a região Sul do Maranhão, tem sua composição geomorfológica formada pela bacia hidrográfica do Rio Farinha e pela Depressão do Médio Vale do Rio Tocantins (IBGE, 2011). Nesse contexto, encontra-se na região a formação de morrarias esculpidas ao longo do tempo através do processo de intemperismo, o que forma um relevo bem particular que recebeu o nome de "mesetas", ou seja, um emaranhado de rochas sedimentares compondo a bacia do rio Parnaíba, originadas de quartzo de arenitos endurecidos formados pelo derramamento de lavas vulcânicas, do tipo basalto com Formação Mosquito e Sambaíba (IBGE, 2011).

Essa paisagem onde foi implantado o Parque Nacional da Chapada das Mesas (PNCM), constitui-se um polo de atração turística que compreende os municípios de Imperatriz, Tasso Fragoso, Estreito, Carolina, Balsas, Riachão, São João do Paraíso e Porto Franco (MARANHÃO, 2011). Mesas:

Segundo Martins et al. (2017, p.627), a região da Chapada das

\begin{abstract}
Está localizada na divisa entre as regiões Norte e Nordeste do Brasil (Maranhão/Tocantins), constitui uma típica paisagem de chapada e tem um importante papel ambiental e ecológico, pelo que, parcialmente, está inserido no Parque Nacional da Chapada das Mesas.
\end{abstract}

PNCM é recente e oferece como atrativo, a formação de grandes paredões rochosos e, junto à vegetação predominante, o Cerrado, e suas fitofisionomias, aliadas às inscrições rupestres e grutas, além de um potencial hídrico com um número significante de nascentes e cachoeiras, os quais formam um cenário geomorfológico que atrai um grande número de frequentadores para prática do ecoturismo e esportes radicais (MARANHÃO, 2011). Salgado et al. (2015) relatam que o PNCM está situado sobre a bacia sedimentar do Rio Parnaíba, sendo uma região que tem sido pouco 
estudada pelos pesquisadores, quanto a sua formação geomorfológica e o processo evolutivo geotectônico e hidrográfico.

Essa Unidade de Conservação (UC) foi a última implantada no Cerrado brasileiro, meta do governo para política pública, como estratégia de conservação de paisagens naturais (SILVA et al., 2017). O processo de criação da área de preservação nessa região surgiu em prol de uma demanda socioambiental, na qual a população temia a construção de duas pequenas hidrelétricas nas cachoeiras que ficam no interior da região, onde atualmente se criou a Unidade de Conservação.

Diante do exposto, o objetivo estudo é apresentar um breve histórico socioambiental do surgimento do Parque Nacional da Chapada das Mesas, desde os primeiros indicativos pelos técnicos do Projeto RADAMBRASIL, até os movimentos com entidades ambientais que lutaram em prol da proposta de sua criação.

A pesquisa é justificada, pelo fato da sociedade civil organizada dos municípios de Carolina, Estreito e Riachão, da área de abrangência do recém-criado Parque, ter a percepção de que a nova UC possibilitaria 0 desenvolvimento econômico da região, com atividades voltadas para turismo ecológico, além de contribuir com a preservação da flora e da fauna desta área de Cerrado ameaçada pelo avanço do agronegócio, principalmente, da produção da soja em larga escala.

\section{Material e Métodos}

\section{Área de Estudo}

Segundo o Instituto Chico Mendes de Conservação da Biodiversidade (ICMBio), o PNCM, abrange os municípios de Carolina, Estreito e Riachão, conforme a Figura 1, classificado como Unidade de Conservação de Proteção Integral, de acordo com a Lei Federal no 9.985/2000, que criou o Sistema de Unidade de Conservação (BRASIL, 2000).

O PNCM está localizado entre as coordenadas 7019'0" S e 47020'06" W (Figura 1). Foi criado com o propósito de preservar uma parte do bioma Cerrado, que nos últimos anos tem sido devastado em larga escala para implantação de grandes projetos do agronegócio, como as monoculturas de soja e arroz, com uso de tecnologias para atender à demanda do mercado internacional (ICMBio, 2016). 


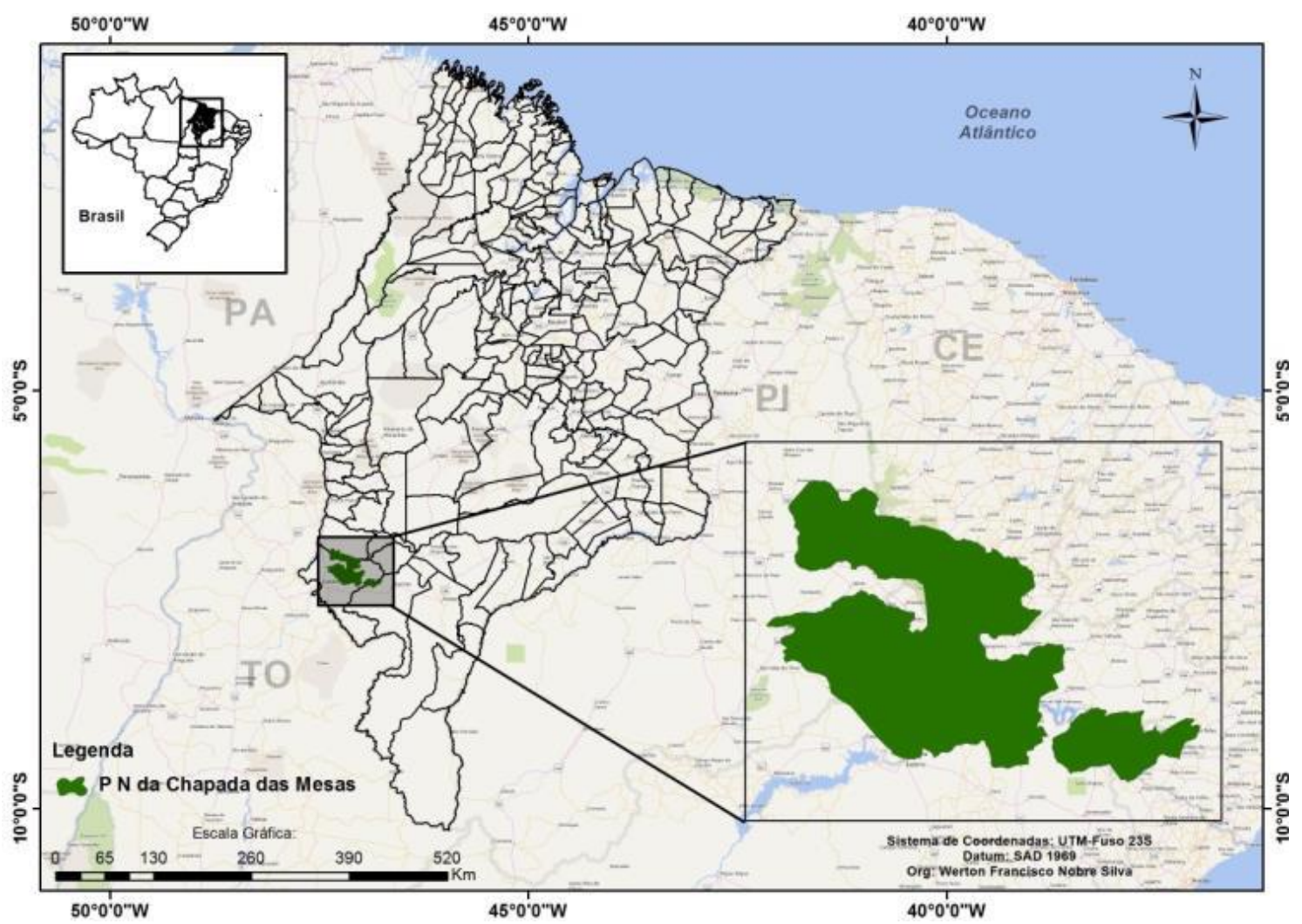

Figura 1: Localização do PNCM no Sul do Maranhão.

Figure 1: Location of the PNCM in the South of Maranhão.

Fonte: MMA, 2015. Organização: Silva (2016).

Source: MMA, 2015. Organization: Silva (2016).

Conforme IBGE (2006) e Martins et al. (2017), a Chapada das Mesas situa-se no centro da unidade geomorfológica formada por Chapadas e Planaltos do Rio Farinha, entre os estados do Maranhão e Tocantins, constituída de belezas cênicas naturais e de grande valor ecológico, em conformidade com elementos paisagísticos exuberantes (Figura 2). Nessa região foi criado o Parque Nacional, através de Decreto Oficial da União, $\mathrm{s} / \mathrm{n}$ de 12 de dezembro de 2005 (BRASIL, 2005), com uma área territorial de 160.040 hectares.

O clima da região é Tropical Úmido, com temperaturas elevadas no decorrer do ano, com duas estações definidas: verão seco nos meses de maio a outubro e, o inverno chuvoso; correspondendo aos meses de novembro a abril, com índices pluviométricos anuais em torno de $1.250 \mathrm{e}$ $1.500 \mathrm{~mm}$ e temperatura média anual em torno de $26^{\circ}$, com base nos dados do Ministério do Meio Ambiente (MMA, 2007). 


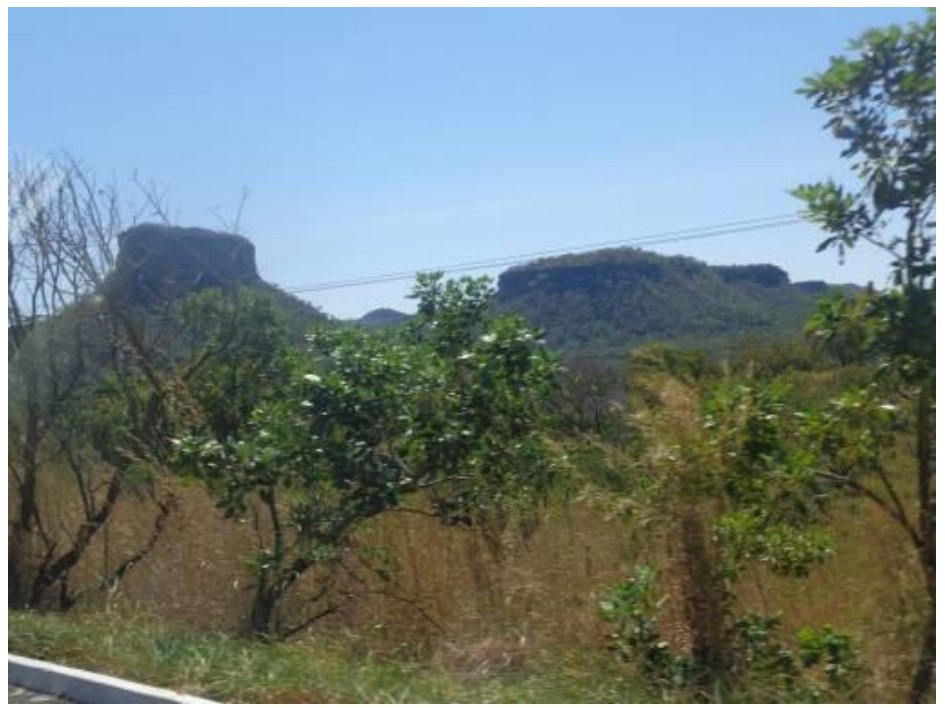

Figura 2: Paisagem natural da região da Chapada das Mesas com a formação de paredões rochosos com formato de "mesetas". Fonte: Dos Autores (2016).

Figure 2: Natural landscape of the Chapada das Mesas region with the formation of rocky walls with "plateau" format. Source: Two Authors (2016).

O estudo teve caráter descritivo, com abordagem qualitativa e com base nas proposições de Minayo (2008). A metodologia obedeceu as seguintes etapas: bibliográfica, de campo e documental. A pesquisa bibliográfica constou de publicações científicas em periódicos, livros e anais de eventos científicos nacionais, como congressos que ressaltam informações teóricas sobre o recém-criado Parque, além de documentos oficiais no ICMBio de Carolina, sites oficiais do Governo Federal que subsidiaram o levantamento histórico e cultural dos primeiros indicativos para criação de uma Unidade de Conservação nessa região do Maranhão, bem como dos movimentos sociais de luta a favor da criação da UC.

Ao se reportar à pesquisa bibliográfica, Gil (2008) relata que ela dá suporte a fatos históricos, quando não se tem outra fonte secundária de informações. O autor enfatiza a importância de documentos como diferencial na pesquisa documental, a diversidade de fontes de materiais utilizados em um estudo científico.

A de campo ocorreu com visitação aos órgãos públicos, tais como a sede regional do ICMBio de Carolina e o museu municipal. Também se fez necessário uso de entrevista semiestruturada, com questões préestabelecidas para um ativista da entidade SOS Rio Farinha, criada em 2000 em prol da UC e um Analista ambiental do Instituto Chico Mendes.

A pesquisa foi submetida à Comissão de Ética Pública, do Centro de Estudos Superiores do Estado do Maranhão (CEP/CESC/UEMA), aprovada com número de protocolo 54126-1, e ao Sistema de Autorização e Informação em Biodiversidade do Instituto Chico Mendes de Conservação e Biodiversidade (SISBIO/ICMBio), com o número de protocolo 5768331650000554, além do Termo de Consentimento Livre Esclarecido (TCLE) aos participantes da pesquisa. 


\title{
Resultados e Discussão
}

\section{Histórico da criação do PNCM a partir da década de 1970}

A primeira proposta de criação do Parque Nacional da Chapada das Mesas surgiu em 1973, através do levantamento e mapeamento de recursos naturais do Brasil, com destaque para o solo, geologia, geomorfologia, vegetação e uso da terra chamado de Projeto RADAMBRASIL (Radar da Amazônia), em 1973, quando foi realizado estudo técnico sobre a geologia, geomorfologia, vegetação e uso potencial da terra no território maranhense.

Nesta perspectiva, Brandão e Theulen (2009) ressaltaram que nos relatórios técnicos foram descritas a formação das chapadas, que receberam uma denominação particular - Mesas de Carolina - e a área indicada para implantação de um Parque Nacional, com base no art. 3ํㅡ, da Lei Federal no 4.771/65 do antigo Código Florestal Brasileiro (BRASIL, 1965).

A nova Unidade de Conservação, envolveria os municípios de Carolina, Estreito, Riachão e Fortaleza dos Nogueiras. No ato da elaboração da proposta de criação da UC para região da Chapada das Mesas, foram traçadas as delimitações para o novo Parque Nacional, sugeridas pelos técnicos do projeto RADAMBRASIL (BRASIL, 1973).

Por volta dos anos 2000, foi criada uma entidade com a participação de pessoas das comunidades dos municípios de Carolina, Riachão e Estreito, intitulado "Movimento SOS Rio Farinha" com objetivo de impedir a criação de duas pequenas hidrelétricas ( $\mathrm{PCHs}$ ), que seriam instaladas nas cachoeiras da Prata e de São Romão no Rio Farinha, situadas onde hoje é a área da UC.

Em entrevista, o representante do Movimento SOS Rio Farinha relata a visita dos técnicos do projeto RADAMBRASIL ao local e as primeiras tentativas para criação da Unidade de Conservação do município de Carolina:

\begin{abstract}
A primeira discussão sobre a criação do Parque Nacional da Chapada das Mesas ocorreu de 1972 a 1973, com o Projeto RADAMBRASIL. Técnicos andaram visitando esta região numa expedição e detectaram que a região era muito bonita, com muitos rios e fizeram um projeto que na época de 210 mil hectares envolvendo os dois lados do asfalto que ainda não existiam até 'topar' no rio Tocantins. Ninguém na época se interessou, eram feitas avaliações, mas por falta de interesse eram engavetadas (Representante do Movimento SOS Rio Farinha, 2017).
\end{abstract}

Quando ocorreu o primeiro diagnóstico das belezas naturais realizado pelos técnicos do Projeto RADAM, a proposta inicial da área territorial da UC seria de $2.100 \mathrm{~km}^{2}$, registrados nos relatórios do Ministério das Minas e Energia, com os limites demarcados e um mapa de localização da futura área de proteção para Carolina. 
Em entrevista, o analista ambiental, declarou:

A demanda de criação da UC se deu por conta do Bioma Cerrado. Foi uma demanda social. No projeto RADAMBRASIL, que foi um projeto de mapeamento do território da Amazônia brasileira, executado pelo serviço de Geografia do Exército Brasileiro, eles passaram em Carolina mapeando o território e viram a importância de criar uma UC por conta da biodiversidade, das belezas cênicas (morrarias) e das riquezas hídricas; já tinham indicado a criação de uma UC nos relatórios entre os anos de 1972 e 1973, que durante muito tempo ficaram engavetados. (Analista ambiental do ICMBio, 2017).

A segunda tentativa aconteceu em 1977, no Planejamento do Sistema Nacional de Unidades de Conservação, através do Instituto Brasileiro de Desenvolvimento Florestal (IBDF), com o nome de "Parque Nacional das Mesas", em que foram traçados os limites da nova UC, com base nos estudos preliminares do projeto RADAMBRASIL. Naquela época, foi criada a minuta de um Decreto Federal e um Relatório Técnico, contendo as descrições naturais da região (BRANDÃO; THEULEN, 2009).

Segundo os sujeitos da pesquisa, estas propostas permaneceram engavetas por algum tempo, mas a partir da década de 1990, as discussões da proposta foram reforçadas pela população carolinense, ainda de maneira tímida.

Em 1992, o Centro Histórico Municipal de Carolina encaminhou o processo à Câmara de Patrimônio do Conselho Estadual de Cultura do Maranhão, para o tombamento do Morro das "Figuras e do Morro das Araras", a descoberta de sítios arqueológicos com a finalidade de preservar os atributos cênicos e desenvolver a pesquisa científica. Em 1993, a assessoria jurídica do Conselho Estadual de Cultura do estado do Maranhão aprovou o pedido de tombamento pelo Centro Histórico de Carolina, posteriormente, publicado no Diário Oficial do Estado com ํㅜ 12.956/1993, de acordo com documentos cedidos pela gestão do PNCM.

Em 1997, o prefeito municipal de Carolina, através de ofício nำ11/97, ao Governo do Estado do Maranhão, solicitou a concessão da construção de $75 \mathrm{~km}$ de estrada encascalhada ligando a BR-010, com vistas a colocar o município de Carolina como Polo Turístico no Sul do Maranhão no roteiro nacional e internacional. No ofício, o prefeito descreveu as belezas cênicas; as cachoeiras; a vegetação nativa do Cerrado com a riqueza biológica de fauna e flora; os mananciais hídricos e as inscrições rupestres, que fazem dessa região, um lugar de grande atratividade turística.

Nos anos de 1998 e 1999, foram realizados estudos e apresentados durante o seminário Avaliação e Identificação de Ações Prioritárias para a Conservação, Utilização Sustentável e Repartição dos Benefícios da Biodiversidade da Amazônia Legal Brasileira e, no seminário, Ações Prioritárias para Conservação da Biodiversidade do Bioma Cerrado e Pantanal, realizado em Brasília, pela Fundação Pró-Natureza; Conservação 
Internacional do Brasil (Cl-Brasil); Fundação Biodiversitas e Universidade de Brasília que tratou da identificação de ambientes considerados prioritários para implantação de áreas protegidas em todo território o brasileiro (BRANDÃO; THUELEN, 2009).

Em setembro de 1999, a Secretaria Municipal de Turismo e Meio Ambiente de Carolina, pelo ofício s/n/99 enviado à Prefeitura Municipal, solicitou a criação do Parque Nacional de Carolina, sendo encaminhado, através de documentação, ao Ministério do Meio Ambiente pelo prefeito municipal da época com relatório sobre a riqueza natural e biológica do lugar. Por meio de relatório informou implantação de projetos e programas de construção de duas usinas hidrelétricas e de barragens no rio Tocantins.

A partir dos anos 2000, a Companhia Paranaense de Energia (COPEL); Grupo Novo Holanda Agropecuária S/A, com sede no município de Balsas/MA; Sistema de Saneamento, Energia e Participações LTDA. (SENERGY); e PLANTARE (Assessoria e Comércio LTDA), receberam a denominação de "Consórcio Rio Farinha", cujo objetivo era elaborar estudos com a finalidade de uso ao poder concedente para autorização dos empreendimentos e a geração de energia elétrica com menor custo, bem como a elaboração e a submissão do projeto à Superintendência de Desenvolvimento da Amazônia, antiga Superintendência do Desenvolvimento do Nordeste (SUDENE).

Em 2001, foi enviado um relatório às autoridades de Carolina alertando sobre os impactos negativos da construção das usinas hidrelétricas de Lajeado, de Estreito/MA e uma nota sobre a construção de Pequenas Centrais Hidrelétrica no Rio Farinha, em Carolina/MA. No caso das PCHs, no Rio Farinha, o relatório apontou que seriam construídas as hidrelétricas nas cachoeiras do São Romão e da Prata, ambas com $15 \mathrm{~m}$ de altura, para aumentar as quedas d'água, uma pequena barragem seria construída acima de cada cachoeira, que formaria pequenos reservatórios contidos no leito do rio (CARVALHO, 2001).

Naquela ocasião foi realizada uma reunião com várias autoridades do município de Carolina sobre o Estudo de Impacto Ambiental e Relatório de Impacto do Meio Ambiente (EIA/RIMA) sobre a construção das usinas no Rio Farinha, especificada nos relatos do representante do Movimento SOS Rio Farinha:

A reunião aconteceu no auditório do Instituto Nacional de Seguridade Social (INSS) de Carolina com várias personalidades da sociedade civil (promotor, vereadores, empresários, prefeito municipal, dentre outras autoridades). No momento da reunião, expliquei aos presentes como funcionaria a usina tecnicamente, os benefícios na região e fora da região. Também expliquei como funcionavam as cachoeiras, sua idade geomorfológica; a alimentação da bacia; dos rios os e dos ecossistemas. O rio Farinha em 2001 já não tinha a mesma capacidade hídrica que tinha antes, eles fizeram o estudo preliminar com base na capacidade hídrica das cachoeiras de 1961, ou seja, depois 
de 40 anos já não tinha mais a mesma capacidade hídrica (Representante do Movimento SOS Rio Farinha, 2017).

Na declaração do representante do Movimento SOS Rio Farinha, no momento da reunião, as autoridades do município de Carolina, como prefeito, vereadores, empresários locais e Governo do Estado ficaram a favor do Consórcio Rio Farinha, alegando que as hidrelétricas instaladas no município trariam maior desenvolvimento econômico e social. Pelas indagações do entrevistado:

\begin{abstract}
Na época, nós fomos chamados de 'Ecoloucos', porque tínhamos a visão de sustentabilidade, não queríamos que destruíssem os rios e as cachoeiras. Na época foram usados veículos de comunicação como rádio, televisão e jornais para mostrar a população da cidade que nós não erámos favoráveis à hidrelétrica e perderíamos as cachoeiras, mostrando para sociedade que se fizessem a usina iríamos perder o grande trunfo de Carolina que era o ecoturismo (Representante do Movimento SOS Rio Farinha, 2017).
\end{abstract}

Neste contexto, em 2004, foi instituído o Decreto Presidencial no 5.092/2004, que colocou o Bioma Cerrado como prioridade para implantação de projetos de unidades de conservação no Brasil, com os demais biomas brasileiros. Esse decreto foi uma estratégia importante para defesa da criação do Parque em estudo, uma vez que a região tem o Cerrado como domínio fitogeográfico (BRASIL, 2004).

Nas proposições do entrevistado, a sociedade de Carolina só despertou para a luta a favor da criação do Parque quando sentiu que iam perder as cachoeiras de São Romão e da Prata. Ele esclarece que a criação das usinas geraria um grande impacto ambiental e social para todos da região da Chapada das Mesas (Figura 3).

O que gerou a expectativa da criação do Parque foi a partir de 1999, quando surgiu um consórcio entre uma empresa do Paraná chamada de COPEL (Companhia Energética do Paraná) com um consórcio do agronegócio da cidade de Balsas chamado Nova Holanda, que queriam construir duas pequenas usinas hidrelétricas no rio Farinha. $\mathrm{O}$ problema não era a construção das usinas, e sim, o local onde queriam construir, que era nas cachoeiras do São Romão (12 megawatts) e da Prata nove (9 megawatts), totalizando uma produção de energia de 21 megawatts. (Representante do Movimento SOS Rio Farinha, 2017). 


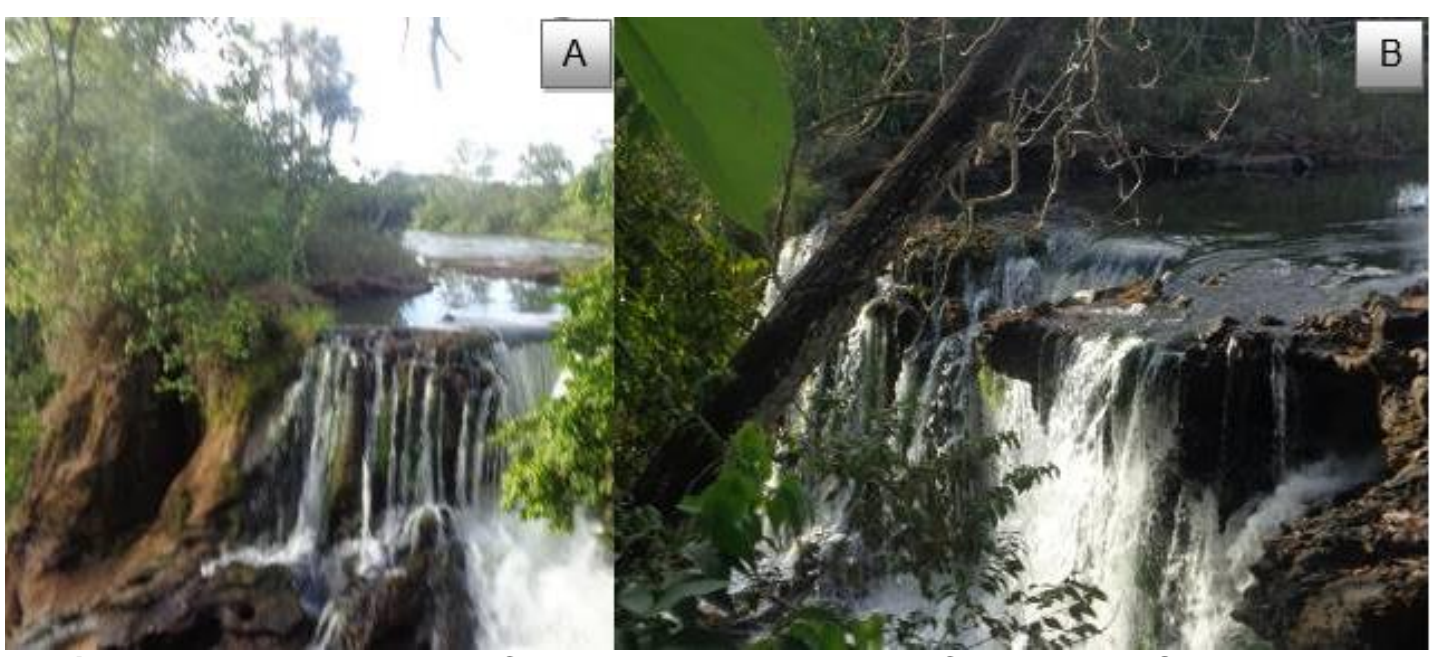

Figura 3: Em A- Imagem da Cachoeira da Prata e em B- Cachoeira do São Romão no PNMC. Fonte: Autores (2016).

Figure 3: In A- Image of the Cachoeira da Prata and in B- Cachoeira do São Romão in the PNMC. Source: Authors (2016)

Abordando o processo histórico de criação do PNCM, o Analista ambiental, comenta:

\begin{abstract}
A luta de criação do Parque reacendeu em 2000, por conta de um projeto de instalação de uma usina hidrelétrica no Rio Tocantins, no município de Estreito. A sociedade civil se organizou e se mobilizou, tanto para barrar a construção da hidrelétrica já que não tinha jeito de barrar, pelos impactos ambientais que poderia causar, quanto para compensar ambientalmente, resgatando o projeto da década de 1970 e da criação de uma UC para esta região (Analista ambiental do ICMBio, 2017).
\end{abstract}

O fato da construção das usinas chamou atenção de segmentos sociais do município de Carolina, que iniciaram os primeiros movimentos em prol da preservação das cachoeiras do São Romão e da Prata. Um dos movimentos que teve destaque para luta contra a instalação das usinas foi o 'Movimento SOS Rio Farinha', com mais de mil assinaturas.

Pelas informações colhidas do representante do Movimento SOS Rio Farinha, o movimento foi se intensificando a favor das cachoeiras e a imprensa começou a publicar matérias em âmbito regional e nacional sobre a reivindicação da sociedade civil, em favor das cachoeiras e da criação da Unidade de Conservação.

Com os apelos da sociedade civil organizada, em 2003, foi protocolada a Indicação no 34/2003, ao Ministério do Meio Ambiente (MMA), o pedido de criação do Parque Nacional e a delimitação territorial da área. Em anexo, um dossiê com o Manifesto pela Conservação dos Cerrados MA/TO, apoiado por 73 entidades com cerca de 1200 assinaturas; Carta Circular no 00/2003 da Associação dos atingidos pela barragem do município de Estreito; ofício no 064/2003 do promotor de justiça da cidade de Carolina ao MMA, solicitando o impedimento da criação das usinas; cópias de Atos 
Judiciais contra a construção das PCHs; Instrumento de Constituição do Consórcio Rio Farinha; a primeira alteração do Instrumento de Constituição; matérias sobre Rio Farinha; mapa do estado do Maranhão e fotos das belezas cênicas de Carolina e Riachão (BRANDÃO; THEULEN, 2009).

Durante a tramitação do processo de criação da UC no MMA, foi realizada a Consulta Pública em 22 de agosto de 2005, na Câmara Municipal de Vereadores de Carolina, com a presença de 80 pessoas que representavam vários segmentos sociais, com destaque para profissionais liberais; representantes dos movimentos sociais em defesa da criação da UC; proprietários de terras; deputados federais; procuradores do Ministério Público Estadual; prefeitos e secretários dos municípios abrangidos e o presidente do Instituto Brasileiro do Meio Ambiente e Recursos Naturais Renováveis (IBAMA) com sede em Imperatriz/MA.

$\mathrm{Na}$ consulta pública, foram apresentados os limites propostos do novo Parque, a legislação específica, a categoria da Unidade de Conservação que foi de Uso Sustentável e as consequências da criação da UC para as pessoas inseridas nos limites do município de Carolina, bem como para sociedade em geral. Após o encerramento, a ata foi lavrada e assinada pelos que se encontravam na plenária, divulgada posteriormente, em jornais impressos e site oficial do IBAMA.

Como procedimento de criação de uma UC, de acordo com a Lei Federal no 9.985/2000, foi realizado um Relatório Técnico com levantamento florístico e fisionômico de comunidades vegetais, cuja coleta, análise e sistematização de dados, assim como informações já existentes, mapas de classificação natural e/ou municipais, levantamentos sistemáticos regionais para caracterização da vegetação. A área de estudo foi determinada através de imagem do satélite LANSDSAT 7 ETM +, bandas 1,5 e 7, escala 1:100.000 com passagem em 14/07/2003, como ponto central das

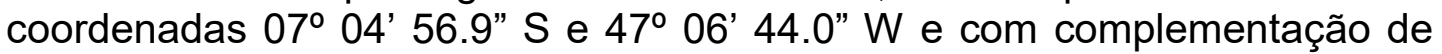
dados utilizando carta planialtimétrica (DSG) da SUDENE, folha: CarolinaSB-23Y-C-II (979), escalas 1:100.000.

Os objetivos do trabalho de campo consistiram em um levantamento dos dados primários, na definição, correlação e ajuste dos diferentes temas e atributos geoambientais presentes e não evidentes na imagem de satélite, além da avaliação precisa das condições ambientais e dos outros elementos atuantes.

A fim de se obterem os objetivos propostos, foram realizadas visitas in loco aos principais ecossistemas, com vistas à obtenção de conhecimento preliminar dos ambientes para facilitar a identificação dos locais ideais para viabilizar o estudo, considerando-se os critérios de homogeneidade e representatividade dos principais tipos fisionômicos em relação às formas de relevo da região com altitudes variando em torno de 500 metros.

$\mathrm{Na}$ metodologia foram observados os fatores ambientais e antrópicos, como referência presente na área onde se implantaria da UC. A pesquisa foi dividida em seis etapas: seleção, análise e interpretação dos documentos cartográficos (mapas, cartas DSG, imagem de satélite, entre 
outros), expedição de reconhecimento, levantamento dos dados fisionômicos e florísticos.

O município de Carolina, pelo estudo técnico está localizado em uma região geográfica considerada estratégica: entre três grandes biomas brasileiros, com espécies de extensa distribuição típica do Cerrado do Planalto Central e outros componentes florísticos de outros biomas como da Floresta Amazônia.

Esta vantagem geográfica favorece a distribuição de comunidades com índice alto de heterogeneidade e ecossistemas compostos a partir de mosaicos vegetacionais que variam de campos abertos até as formações de florestas mais densas, mesmo que a região tenha como formação vegetal o cerrado sensu stricto. As espécies florísticas coletadas foram identificadas com a literatura especializada e classificadas conforme a família, com identificação do nome científico, nome vulgar e hábito.

$\mathrm{Na}$ introdução do relatório, para o levantamento da avifauna, ressaltou-se que ao Norte do Cerrado, pelas proposições de Silva (1995), encontram-se algumas lacunas do conhecimento avifaunístico que datam dos anos de 1990. Recentemente, têm destaque os inventários de Braz et al. (2003), com os faunísticos do Parque Estadual do Mirador/MA e do Jalapão/TO; Zaher (2001), na Estação Ecológica de Uruçuí/PI e Santos (2001), com Área de Proteção Ambiental (APA) Serra da Tabatinga e Chapada das Mangabeiras no Sul do Maranhão.

A área que foi inventariada no estudo localiza-se entre 60-90 km a Leste de Carolina, no bioma Cerrado e foram divididas pela altitude: regiões planas de baixa altitude são dominadas por Cerrado stricto sensu, formadas por vegetação savânica de estratos arbóreos, arbustivos e herbáceos, com porte de até $7 \mathrm{~m}$; vegetação de Campos cerrados, paisagem menos densa, com árvores menos comuns, de altura menor que o stricto sensu; próximos aos cursos dos rios são encontrados matas de galeria com árvores de até $25 \mathrm{~m}$ de altura; veredas formadas por campo alagados e palmeiras isoladas; campos limpos e campos sujos (EITEN, 1993).

Para realização do inventário, percorreram-se, nos dias 20 a 25 de outubro de 2005, manchas de vegetação como, por exemplo, Cerrado Stricto sensu, mata de galeria, identificando as espécies de aves, registradas com o auxílio de binóculos e equipamento bioacústico (gravador SONY TCM 5000EV e microfone direcional Sennheir 600 long.). A área amostrada somou um total de cinco locais em diversos ambientes, em uma distância de $3 \mathrm{~km}$, com a perspectiva de registrar as aves existentes na vegetação que foram selecionadas para o estudo.

Foram encontradas 8 (oito) espécies endêmicas para região de Cerrado, sendo 07 (sete) associadas à vegetação aberta (savana), conforme Silva (1997) e Cavalcanti (1999). Registraram-se espécies de bico-depimenta (Saltator atricollis), bandoletas (Cypsnagra hirundinaceas), macaquinho-do-cerrado (Melcanopareia torquata), mineirinho (Charitospiza eucosma), gralha-do-cerrado (Cyanocorax eristatellus), papagaio curau 
(Amazona xanthops), choca (Thamnophilus torquatus) e uma única espécie relacionada à área de floresta: chorozinho (Herpsilochus longinosti).

Collar et al. (1992) e Braz et al. (2003), tinham identificado 4 (quatro) espécies de aves ameaçadas de extinção: o ferreiro (Procnias averano), urubuzinho (Chelidoptera tenebrosa) de ambiente Amazônico, periquito da caatinga (Aratinga cactum), joão-tenerém (Synallaxis spixi) e galo- decampina (Paroaria dominicana), sendo os últimos encontrado em regiões com presença de manchas do bioma Caatinga.

No parecer final do relatório, indicou-se a criação do Parque Nacional que irá contribuir com a preservação da avifauna do Norte do Cerrado, a qual possui 361 espécies de aves já registradas. No levantamento, as espécies foram identificadas conforme literatura especializada e classificadas de acordo com a família, com nome científico e vulgar, frequência, ambiente encontrado, horário e frequência por grupo encontrado.

Por último, foi elaborada a Base da Cartografia da Proposta de criação do Parque Nacional da Chapada das Mesas, que foram cedidos pelo Sistema de Proteção da Amazônia. Para tanto, foram utilizados os dados cartográficos na escala 1:100.000 do estado do Maranhão, como suporte ao projeto cartográfico do Parque, e para garantir eficiência na análise desses dados, foram convertidos no programa DWG, DGN para o "shapefle", utilizado pelo IBAMA.

As informações estavam no formato de arquivos e níveis com separação de acordo com o tema e abrangência espacial. Sendo que o modelo de dados foi compatível com o software Arcview, versão 3.2. A nomenclatura dos arquivos e o conceito dos campos nas tabelas de atributos foram compatíveis com as informações na versão "Shapefile" e as coordenadas foram localizadas no sistema UTM, em tabela com dados de cada atributo e tema, colocados em quatro arquivos com os elementos gráficos do polígono do tipo de linha, pontos e toponímia.

No dia 08 de agosto de 2005, às duas imagens de satélite CBERS, posteriormente, foram georreferenciadas para elaboração do limite da nova UC, com a edição dos dados e digitalização dos vetores que não constam na base cartográfica. Após digitalização, a base cartográfica digital na escala 1:100.00 na projeção UTM com os arquivos foram gerados e organizados no banco de dados cartográficos do IBAMA e disponibilizados em CD-Rom para a elaboração desta Nota Técnica.

Após a análise do Relatório Técnico, foi dado parecer favorável à criação da UC, sugerindo a mudança da categoria de Uso Sustentável para de Úso Integral, de acordo com a Lei Federal no 9.985/2000, considerando que o Cerrado é um dos '“hotspot" mundiais' de biodiversidade. Em setembro de 2005, o IBAMA encaminhou cópia do processo $\mathrm{n}^{\text {0 }}$ 02001.003252/2005-29/MMA ao Presidente da República e ofício GP/s/n/2005 para a criação do Parque Nacional da Chapada das Mesas, nos municípios de Carolina, Estreito e Riachão, no estado do Maranhão, com o mapa de delimitação da área territorial (Figura 4). 

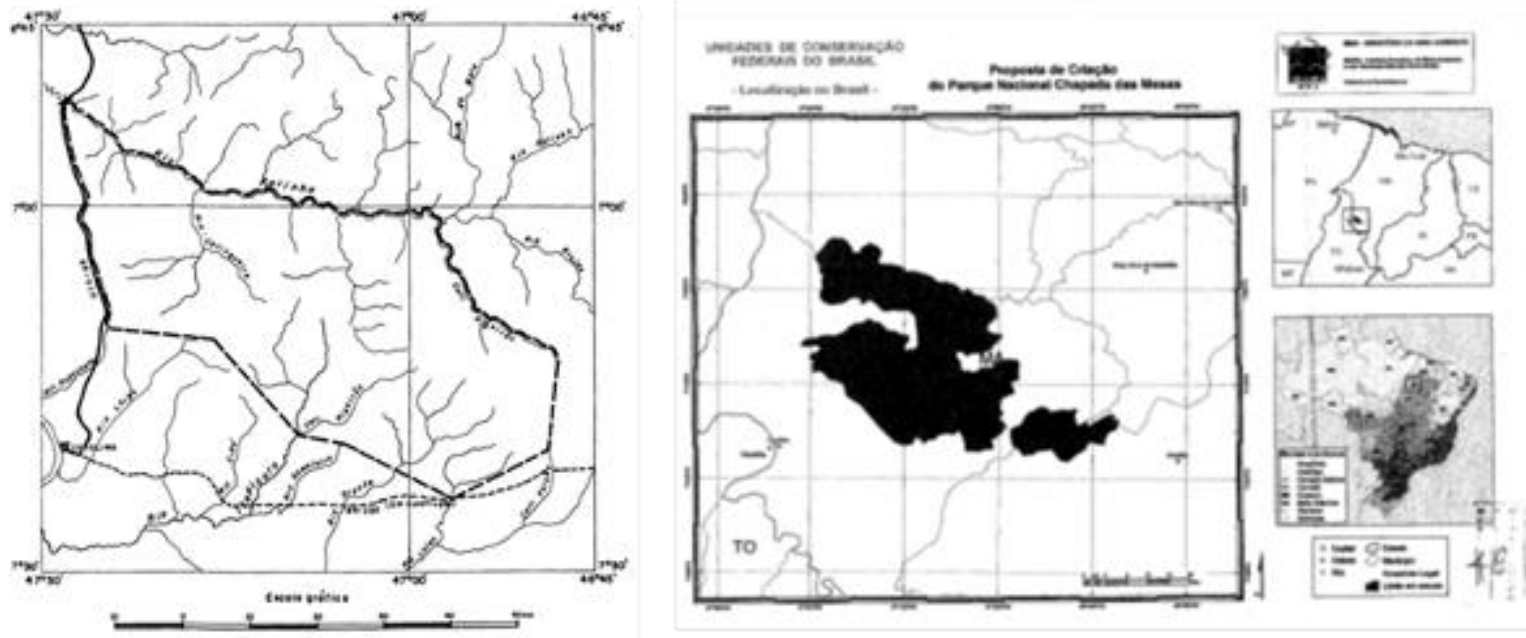

Figura 4: Em A - Proposta do mapa de localização do PNCM projetado pelo Projeto RADAMBRASIL (1970) e em B - Mapa de localização do Parque diagramado pelo IBAMA (2005). Fonte: Arquivo do ICMBIO de Carolina (2017).

Figure 4: In A - Proposal of the PNCM location map projected by the RADAMBRASIL Project (1970) and in B - Map of the Park location diagrammed by IBAMA (2005). Source: Carolina ICMBIO Archive (2017).

Pelas informações obtidas em documentos sobre o resgate histórico e socioambiental do Parque Nacional em estudo e os relatos dos sujeitos da pesquisa, entende-se que o novo Parque Nacional criado nesta área de Cerrado no Maranhão surgiu tendo em vista à sensibilidade dos seus moradores que perceberam a importância da preservação da riqueza biológica e dos recursos naturais e o potencial turístico na promoção de geração de renda, conforme (Figura 5), incorporado a visão de sustentabilidade.

Pelas imagens da Figura 5, os municípios situados na área do entorno da UC têm investido na construção de pousadas, hotéis, risotes, atendendo aos visitantes com passeios guiados para conhecer as belezas cênicas e naturais; outros investimentos estão em crescimento, como o artesanato local e o setor de alimentação com pratos típicos da culinária regional. 


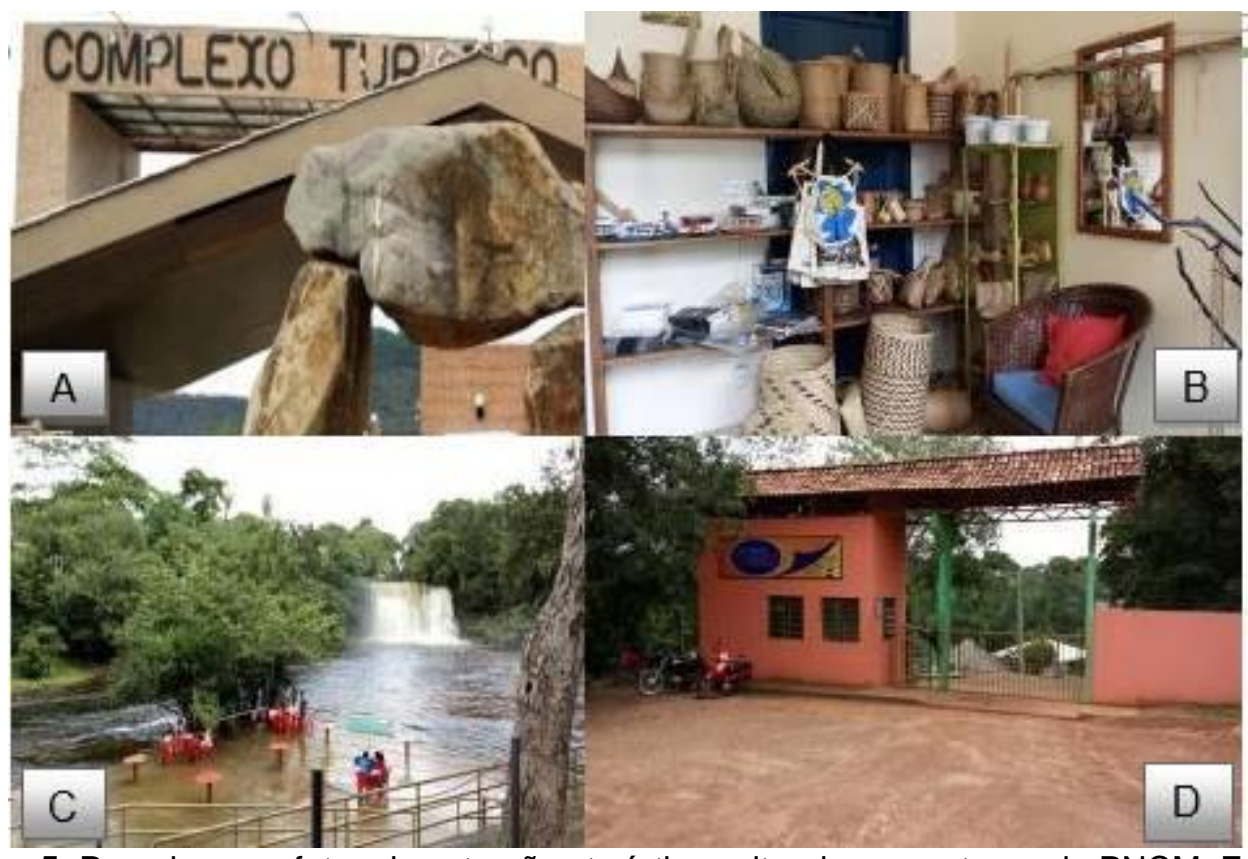

Figura 5: Prancha com fotos das atrações turísticas situadas no entorno do PNCM. Em A Complexo Pedra Caída, B - Loja de Artesanato em Carolina, C- Pousada do Itapecuruzinho e D- Fachada da Cachoeira da Prata. Fonte: Dos Autores (2017).

Figure 5: Surfboard with photos of the tourist attractions located around the PNCM. In A Complejo Pedra Caída, B - Craft Shop in Carolina, C- Pousada do Itapecuruzinho and DFaçade of the Cachoeira da Prata. Source: Two Authors (2017)

\section{Considerações Finais}

O Parque Nacional da Chapada das Mesas, criado em 2005, como política do Governo Federal para expandir áreas protegidas no Cerrado, foi uma luta dos moradores dos municípios de sua área de abrangência, fatos evidenciados em documentos encontrados no acervo do ICMBio de Carolina e com o depoimento dos atores sociais que participaram da entrevista que retratam o contexto histórico para criação da UC.

Nos arquivos, verificou-se que em 1988, iniciou-se um estudo com a finalidade de criar ações prioritárias para conservação da biodiversidade dos biomas brasileiros. Naquela época, foram realizados seminários visando às políticas de criação da UC na região da Amazônia Legal do bioma Cerrado e Pantanal, sendo a região de Carolina uma das indicadas para criação de áreas protegidas, devido às suas belezas cênicas, à vegetação e por se tratar de uma área de ecótono e riqueza hídrica. Outro fato que estimulou a criação da UC foi a mobilização da sociedade civil organizada, que lutou contra a construção de duas pequenas hidrelétricas nas cachoeiras do Rio Farinha. Essa luta se deu para preservar as cachoeiras do São Romão e da Prata para o desenvolvimento do ecoturismo, tornando esta região um polo de turismo ecológico regional, nacional e internacional.

A implantação do Parque Nacional trouxe uma nova perspectiva de utilização dos recursos naturais com a inserção da prática do turismo sustentável. Observou-se que após a criação da Unidade de Conservação, houve o aumento do número de turistas de várias regiões do Brasil e fora do 
país para conhecer as paisagens naturais, gerando renda e novas oportunidades de trabalho para os habitantes locais, sem contar com a preservação dos sistemas ecológicos.

Ressalta-se neste contexto, que a participação dos poderes do executivo estadual e municipal poderão colaborar com ações de infraestrutura, tais como: melhorias na malha viária, com asfaltamento de rodovias de acesso ao Parque; sistema de eletrificação, com maior eficiência; e investimentos no saneamento básico (abastecimento de água e esgoto e coleta de lixo com a construção de aterros sanitários). Estas são medidas que impulsionam o turismo dos municípios de abrangência da UC da Chapada das Mesas, impactando diretamente na melhoria da vida dos habitantes locais que passam a contar com a geração de emprego e renda, notadamente, no setor de serviço do turismo e do comércio e para os visitantes que usufruirão dos serviços e da contemplação das belezas naturais.

\section{Referências}

BRASIL, DEPARTAMENTO NACIONAL DE PRODUÇÃO MINERAL. Programa RADAM BRASIL. Folha SB.23. Teresina e parte da folha SB. 24 Jaguaribe. Geologia, geomorfologia, solos, vegetação e uso potencial da terra. Rio de Janeiro, 1973. Disponível em http://www.bdpa.cnptia.embrapa.br/.../busca?b=ad...Brasil...Brasil...t.. Acesso em: 21. Dezembro. 2018.

BRASIL, Lei $\mathrm{n}^{\circ}$ 4.771, de 15 de setembro de 1965. Institui o Código Florestal. Disponível em http://www2.camara.leg.br/.../lei/.../lei-4771-15setembro-1965-369026-publicacaooriginal-. Acesso em: 22. Abril. 2018.

BRASIL, Lei no 9.985, de 18 de julho de 2000. Dispõe sobre o Sistema Nacional de Unidades de Conservação. Disponível www.mma.gov.br/ areas-protegidas/unidades-de.../sistema-nacional-de-ucs-snuc.html. Acesso em: 18. Abril. 2018.

BRASIL, Decreto Federal no 5.092 de 21 de maio de 2004. Define regras para identificação de áreas prioritárias para a conservação, utilização sustentável e repartição dos benefícios da biodiversidade, no âmbito das atribuições do Ministério do Meio Ambiente. Disponível em http://www.planalto.gov.br/ccivil_03/_ato2004-2006/2004/decreto/d5092.htm. Acesso em: 07. Set. 2018.

BRASIL, CONSERVAÇÃO INTERNACIONAL DO BRASIL. Relatório Técnico da criação do Parque Nacional da Chapada das Mangabeiras, Carolina MA. Palmas, 2005, 39 p.

BRASIL, Decreto Federal s/n de 12 de dezembro de 2005. Cria o Parque Nacional da Chapada das Mesas, nos municípios de Carolina, Riachão e Estreito no estado do Maranhão e dá outras providências. Disponível em http:// www.icmbio.gov.br > Página inicial > Unidades de Conservação. Acesso em: 21. Julho. 2018. 
BRAZ, V.S.; ABREU, T.L.S.; LOPES, L.E.; LEITE, L.O.; FRANÇA, F.G.R.; VASCONCELLOS, M.M.; BALBINO, S.F. Brazilian Merganser Mergus octosetaceus discovered in Jalapão State Park, Tocantins, Brazil. Cotinga, n.20, 2003, p.68-71.

BRANDÃO, R.A; THEULEN, V. O mais novo nunca foi novidade. 2009. Disponível em http://www.oeceo.com.br/colunas/reuber-brandão-e-verônicatheulen. Acesso em: 05. Abril. 2018.

COLLAR, N.J.; L.P. GONZAGA; N. KRABBE; A. MADROÑO NIETO; L.G. NARANJO; T.A. PARKER III; D.C. WEGE. Threatened Birds of the Americas. Washington DC, Smithsonian Institution Press, 1992, 1150p.

CARVALHO. N.O. RELATÓRIO TÉCNICO SOBRE A USINA HIDRELÉTRICA DE LAJEADO. Como Afetará Carolina. Rio de Janeiro, 2001.

CARVALHO, N. O. NOTA TÉCNICA. Construção da Usina de Estreito/MA e providências necessárias para melhor benefício das populações atingidas. Rio de Janeiro, 2001.

CARVALHO, N. O. NOTA TÉCNICA. Construção de pequenas centrais hidrelétricas no rio Farinha. Rio de Janeiro, 2001.

CAVALCANTI, R.B. Bird species richness and conservation in the Cerrado region of Central Brazil. Studies in Avian Biology, n.19, p. 244-249, 1999.

EITEN, G. Classificação da vegetação do Brasil. Brasília: CNPq, 1983. $305 p$.

GIL, A. C. Métodos e técnicas de pesquisa social. 6. ed. São Paulo: Atlas, 2008.220p.

INSTITUTO BRASILEIRO DE GEOGRAFIA E ESTATÍSTICA - IBGE. Geomorfologia: mapa geomorfológico do estado do Maranhão. Rio de Janeiro, 2011.

INSTITUTO BRASILEIRO DE GEOGRAFIA E ESTATÍSTICA - IBGE. Mapa de Unidades do Relevo do Brasil. Escala 1: 5.000.000, 2006. Disponível http://geoftp.ibge.gov.br/mapas tematicos/mapas murais/relevo 2006.pdf.

Acesso em: 22. Abril. 2018.

INSTITUTO CHICO MENDES DE CONSERVAÇÃO DA BIODIVERIDADES ICMBIO. 2016. Nota técnica № 001/2016. Carolina/MA. Disponível em: http://dlij67glom3ric.cloudfront.net. Acesso em: 20. Setembro. 2018.

MINISTÉRIO DO MEIO AMBIENTE - MMA. Centro Nacional de Prevenção e Combate aos Incêndios Florestais - Prevfogo. Parque Nacional da Chapada das Mesas. Plano operativo de prevenção e combate aos incêndios florestais do Parque Nacional da Chapada das Mesas 2007. Disponível em

http://www.ibama.gov.br/plano operativo parna da chapada das mesas.

Acesso em: 23. Março. 2018.

MINAYO, M. C.S. O desafio do conhecimento. 11 ed. São Paulo: Hucitec, 2008. 
MARANHÃO. SECRETARIA DE ESTADO DO PLANEJAMENTO, ORÇAMENTO E GESTÃO. Rede de Gestão Ambiental do Maranhão REGEAMA (NUGEO/UEMA). Plano de ação para Prevenção e controle do desmatamento e das queimadas no Estado do Maranhão. São Luís, 2011.

MUNIZ, F. H. A vegetação da região de transição entre a Amazônia e o Nordeste: diversidade e estrutura. In: MOURA, E. G. de. (Org.). Agroambientes de transição entre o Trópico Úmido e o Semiárido do Brasil: atributos, alterações e uso na produção familiar. $2^{a}$ ed. São Luís: Programa de Pós-graduação em Agroecologia/UEMA, v. 1, 2006, p. 53-69.

MARTINS, F. P.; SALGADO, A. A. R.; BARRETO, H. N. Morfogênese da Chapada das Mesas (Maranhão-Tocantins): paisagem cárstica e poligenética. Revista Brasileira de Geomorfologia (Online), São Paulo, v.18, n.3, p.623-635, 2017.

MARQUES, A. R.; AMORIM, M. C. C. T. Saberes geográficos aos estudos territoriais sob a ótica da implantação do Parque Nacional da Chapada das Mesas, sertão de Carolina/MA. Revista Geografia em Questão. v. 7, n. 2, p.18, 2014.

SANTOS, M.P.D. Composição da avifauna nas áreas de proteção ambiental serra da Tabatinga e Chapada das Mangabeiras, Brasil. Emílio Goeldi, série. zool. n.17,v.1, 2001.

SILVA, J.M.C. Birds of the Cerrado Region, South America. Steentrupia. v.21, n.2, p.69-92, 1995.

SALGADO, A.A.R.; BUENO, G.T.; DINIZ, A. D.; MARENT, B. R. Long-Term Geomorphological Evolution of the Brazilian Territory. (Org.) VIEIRA B.C.; SALGADO A.A.R.; SANTOS. L.J.C. Landscapes and Landforms of Brazil, London: Springer, 2015, p. 19-31.

SILVA, J.M.C. Endemic bird species and conservation in the Cerrado Region, South America. Biodiversity and Conservation, v.6, n, p.435-450, 1997.

SIVA, M.L.A.; ARAÚJO, M.F.V.; CONCEIÇÃO, G, M. Identidade e modo de vida dos moradores do Parque Nacional da Chapada das Mesas, Maranhão, Brasil. Biota Amazônia. v. 7, n. 4, p. 41-47, 2017.

ZAHER, H. E. D. Projeto: Diversidade de Vertebrados Terrestres da Estação Ecológica de Uruçuí-Una, Piauí: subsídios para o plano de manejo. Curitiba. Fundação O Boticário, 2001, 110p. 
Maria Lindalva Alves da Silva: Universidade Estadual do Maranhão, São Luís, MA, Brasil.

E-mail: marialindalvaa@gmail.com

Link para o currículo Lattes: http://lattes.cnpq.br/3004179759769388

Maria de Fátima Veras Araujo: Universidade Estadual do Piauí, Teresina, PI, Brasil.

E-mail: maria.fveras2018@gmail.com

Link para o currículo Lattes: http://lattes.cnpq.br/5210437800253488

Gonçalo Mendes da Conceição: Universidade Estadual do Maranhão, Caxias, MA, Brasil.

E-mail: doutorgoncalo@gmail.com

Link para o currículo Lattes: http://lattes.cnpq.br/0605946383963749

Data de submissão: 27 de dezembro de 2018

Data de recebimento de correções: 13 de abril de 2019

Data do aceite: 13 de abril de 2019

Avaliado anonimamente 